\title{
Transport and Dynamics of the Panay Sill Overflow in the Philippine Seas*
}

\author{
ZACHARY D. TESSLER AND ARNOLD L. GORDON \\ Lamont-Doherty Earth Observatory, Palisades, New York \\ LARRY J. PRATT \\ Woods Hole Oceanographic Institution, Woods Hole, Massachusetts \\ JANET SPRINTALL \\ Scripps Institution of Oceanography, La Jolla, California
}

(Manuscript received 3 November 2009, in final form 12 August 2010)

\begin{abstract}
Observations of stratification and currents between June 2007 and March 2009 reveal a strong overflow between 400- and 570-m depth from the Panay Strait into the Sulu Sea. The overflow water is derived from approximately $400 \mathrm{~m}$ deep in the South China Sea. Temporal mean velocity is greater than $0.75 \mathrm{~m} \mathrm{~s}^{-1}$ at $50 \mathrm{~m}$ above the 570-m Panay Sill. Empirical orthogonal function analysis of a mooring time series shows that the flow is dominated by the bottom overflow current with little seasonal variance. The overflow does not descend below $1250 \mathrm{~m}$ in the Sulu Sea but rather settles above high-salinity deep water derived from the Sulawesi Sea. The mean observed overflow transport at the sill is $0.32 \times 10^{6} \mathrm{~m}^{3} \mathrm{~s}^{-1}$. The observed transport was used to calculate a bulk diapycnal diffusivity of $4.4 \times 10^{-4} \mathrm{~m}^{2} \mathrm{~s}^{-1}$ within the Sulu Sea slab $(\sim 575-1250 \mathrm{~m})$ ventilated from Panay Strait. Analysis of Froude number variation across the sill shows that the flow is hydraulically controlled. A suitable hydraulic control model shows overflow transport equivalent to the observed overflow. Thorpe-scale estimates show turbulent dissipation rates up to $5 \times 10^{-7} \mathrm{~W} \mathrm{~kg}^{-1}$ just downstream of the supercritical to subcritical flow transition, suggesting a hydraulic jump downstream of the sill.
\end{abstract}

\section{Introduction}

Exchange between ocean basins often occurs in regions of confined straits with relatively shallow topographic sills. The effects of shallow topography on water characteristics and flow dynamics are important for a full understanding of regional and global ocean circulation and deep basin ventilation. The archipelago stretching from Asia to Australia, separating the Pacific and Indian Oceans, consists of many deep basins isolated from each other and the open ocean by relatively shallow sills. Parts of this archipelago have been intensively studied, including the ventilation of the deep

* Lamont-Doherty Earth Observatory Contribution Number 7386.

Corresponding author address: Zachary D. Tessler, LamontDoherty Earth Observatory, 61 Route 9W, Palisades, NY 10964. E-mail: ztessler@1deo.columbia.edu basin in the Banda Sea through the Lifamatola Passage, by van Aken et al. (2009), and the deep ventilation of the South China Sea via Luzon Strait, investigated by Chao et al. (1996) and Qu et al. (2006b).

Similarly, the seas of the Philippines region are composed of numerous isolated deep basins, though the circulation patterns that ventilate these basins and the physical processes that modify these water masses have not been discussed as widely in the literature. This is despite the high level of paleoceanographic work done in the region to study changes in El Niño-Southern Oscillation, the Asian monsoon, and the intertropical convergence zone over climatic time scales (Oppo et al. 2003; Dannenmann et al. 2003).

Early work in the region by Wyrtki (1961) identified the role of the Asian monsoon in directing the surface flow between the South China Sea and the Sulu Sea. Geochemical work using radiocarbon dating has traced Sulu Sea deep water to sources in the South China Sea (Broecker et al. 1986), and sediment cores show evidence 


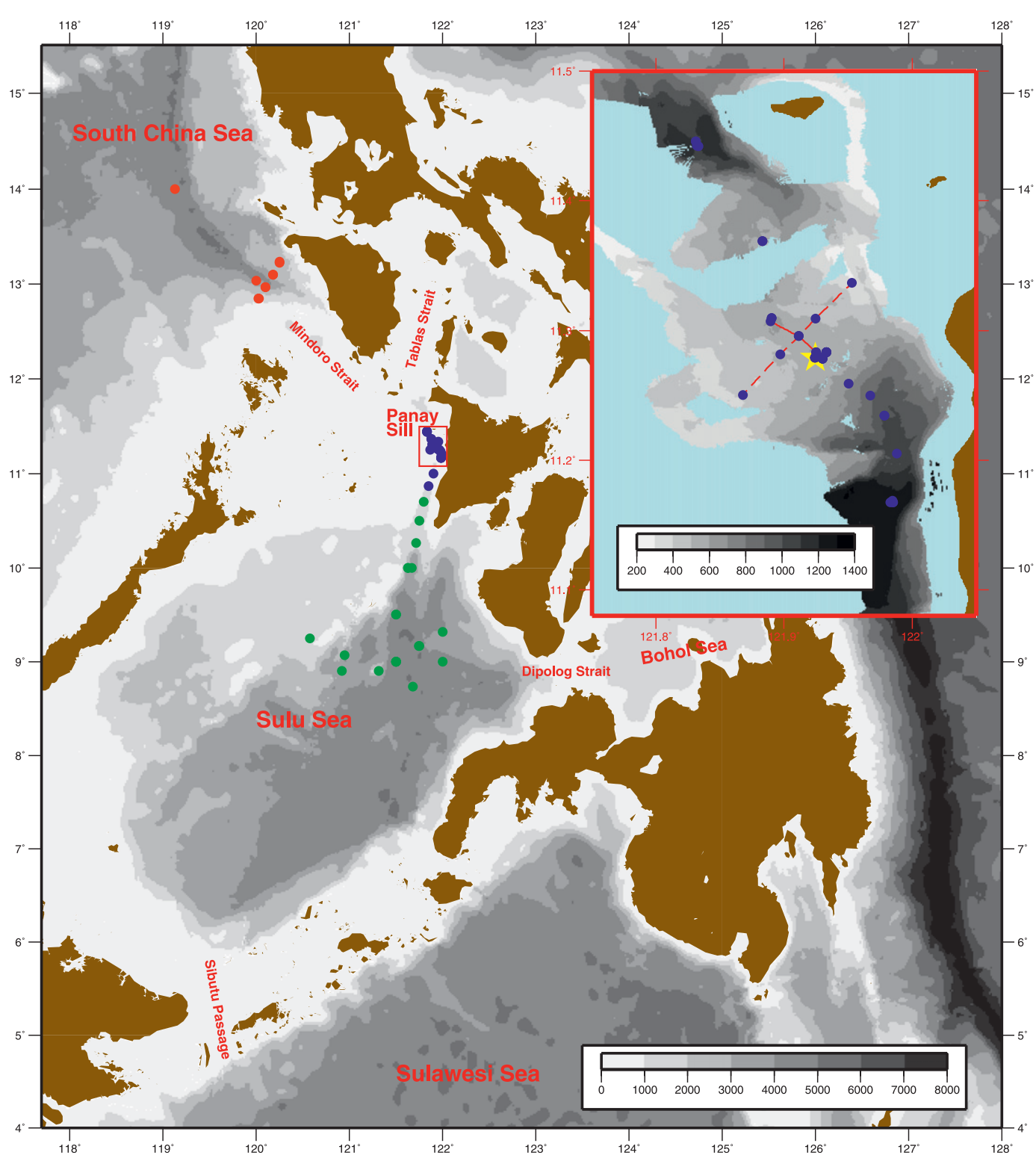

FIG. 1. Map of the study region. Large map bathymetry is from Smith and Sandwell (1997), v12.1: resolution is $1^{\prime}$. Inset bathymetry is multibeam data collected during sampling in 2008 and 2009. CTD/LADCP station colors identify South China Sea (red), Panay Sill (blue), and Sulu Sea (green) stations, and the yellow star is the mooring location. Inset dashed line identifies stations used in channel cross sections in Fig. 8. Inset solid line connects along-channel control volume stations.

of periodic turbidity currents flowing down from Mindoro Strait into the Sulu Sea (Quadfasel et al. 1990). Given the shallower depths of other sills surrounding the Sulu Sea, these studies suggested that the southward flow of subthermocline South China Sea water into the Sulu Sea by way of Mindoro Strait may be the dominant, if not the only, source of Sulu Sea deep water. However, based on observations presented below, Mindoro Strait water appears not to ventilate the deep Sulu Sea.
The Mindoro Strait consists of two sills, the northern Mindoro Sill at approximately 440-m depth and Panay Sill at $570 \mathrm{~m}$, separated by a small basin near the Tablas Strait with depths up to $1000 \mathrm{~m}$ (Fig. 1). Qu and Song (2009) used satellite-derived sea surface height and ocean bottom pressure to estimate a total mean transport from the South China Sea to the Sulu Sea through Mindoro Strait of $2.4 \mathrm{~Sv}\left(\mathrm{~Sv} \equiv 1 \times 10^{6} \mathrm{~m}^{3} \mathrm{~s}^{-1}\right)$, with strong seasonal variability. Additionally, the ocean general circulation 
model for the Earth Simulator measured the flow through Mindoro Strait at 1.3 Sv (Qu et al. 2006a).

Here we present direct overflow measurements at a topographic sill within Panay Strait, using both lowered and moored acoustic Doppler current profilers (ADCPs). Our focus is on the strong flows observed in the benthic boundary layer. Transport estimates for this overflow are based on both the direct measurements and a hydraulic control model using available hydrographic data. In section 2, we describe the data, including the conductivitytemperature-depth (CTD), lowered ADCP (LADCP), and moored ADCP. Transport estimates using observed current data and hydraulic control theory are presented in section 3; the dynamics of the overflow, including flow criticality and diapycnal mixing estimates, are in section 4. In section 5, we discuss how the direct observations compare to the hydraulic control theory estimates and what our results mean in terms of downstream ventilation of the Sulu Sea.

\section{Data}

Data was collected as part of the Philippines Straits Dynamics Experiment (PhilEx) on three cruises aboard the R/V Melville during June 2007, January 2008, and March 2009. For this study we will be using a subset of the complete dataset (Fig. 1). This subset includes data from CTD and LADCP casts and a bottom-moored ADCP. In 2007, 7 CTD/LADCP stations were taken in the vicinity of Panay Sill, 15 in 2008, and 6 in 2009. Of these, a total of eight stations were occupied at the mooring location: six in 2007 and one each in 2008 and 2009. Three other locations near the sill were occupied on multiple cruises. Figure 2 shows a profile of data taken from a representative station at Panay Sill. Station casts were not taken with regard for the tidal cycle, which introduces a potentially important source of uncertainty, particularly in the LADCP data.

\section{a. $C T D$}

The CTD system included a SeaBird Electronics SBE911 + CTD system fitted with two sets of dual pump conductivity and temperature sensors and an SBE43 dissolved oxygen sensor. The SeaBird temperature sensor has a manufacturer-reported accuracy of $0.001^{\circ} \mathrm{C}$. The conductivity sensor is accurate to $0.0003 \mathrm{~S} \mathrm{~m}^{-1}$. Water samples were collected in six 10-L bottles using a 12-position carousel. Conductivity calibration was performed in a temperature-controlled shipboard laboratory using a Guildline Autosal 8400A laboratory salinometer. Downcast data was processed to a 1-dbresolution temperature and salinity product from which surface-referenced potential temperature and potential density were calculated.

\section{b. Lowered ADCP}

Lowered ADCP instruments were deployed in a twohead configuration attached to the CTD rosette. In 2007 and 2008 a custom-built high-powered Teledyne RDI $300-\mathrm{kHz}$ instrument was used as a downlooker and a Teledyne RDI Workhorse $300-\mathrm{kHz}$ instrument was used as an uplooker. In 2009, two regular Teledyne RDI Workhorse $300-\mathrm{kHz}$ instruments were used in the uplooker/downlooker configuration. The instruments were configured to collect staggered single ping ensembles every 1.5/2.0 s. Processing was done using the Lamont-Doherty Earth Observatory LADCP Processing Suite software, incorporating CTD data for correction of ADCP range due to sound speed variation, and hull-mounted ADCP, GPS, and bottom-tracking for constraints on the barotropic velocity (Visbeck 2002).

\section{c. ADCP mooring}

An upward-looking Teledyne RDI Long Ranger $75-\mathrm{kHz}$ moored ADCP at Panay Sill $\left(11^{\circ} 16^{\prime} \mathrm{N}, 121^{\circ} 55^{\prime} \mathrm{E}\right)$ was deployed at approximately $570 \mathrm{~m}$ (578-m water depth) on 9 June 2007. The mooring was located $2.5 \mathrm{~km}$ downstream from the narrowest constriction at Panay Sill. On 28 June 2007 the mooring was recovered, the data downloaded, and then redeployed at the same site. A second recovery and redeployment was conducted on 5 December 2007. This final deployment lasted until recovery on 16 March 2009. The instrument recorded a ping ensemble every $30 \mathrm{~min}$ with a bin size of $16 \mathrm{~m}$ interpolated onto a $10-\mathrm{m}$ grid. ADCP depth was pressure corrected for mooring motion, though corrections were small owing to the short 8-m wire length from the ADCP instrument mount to the bottom anchor.

\section{Panay Sill overflow transport}

\section{a. Water characteristics}

The overflow water is drawn from the South China Sea, which in turn draws water from the western Pacific via Luzon Strait (Qu et al. 2006a). Repeat LADCP observations (Fig. 3) across the topographic sill of the Panay Strait reveal strong bottom-intensified flow to the south. The flow is strongest on the steep downstream side of the sill, weakening as the seafloor slope decreases away from the sill.

Subthermocline water at the sill shows a sharp density interface approximately $100 \mathrm{~m}$ above the seafloor (e.g., Fig. 2). The mean depth of this interface across the eight 


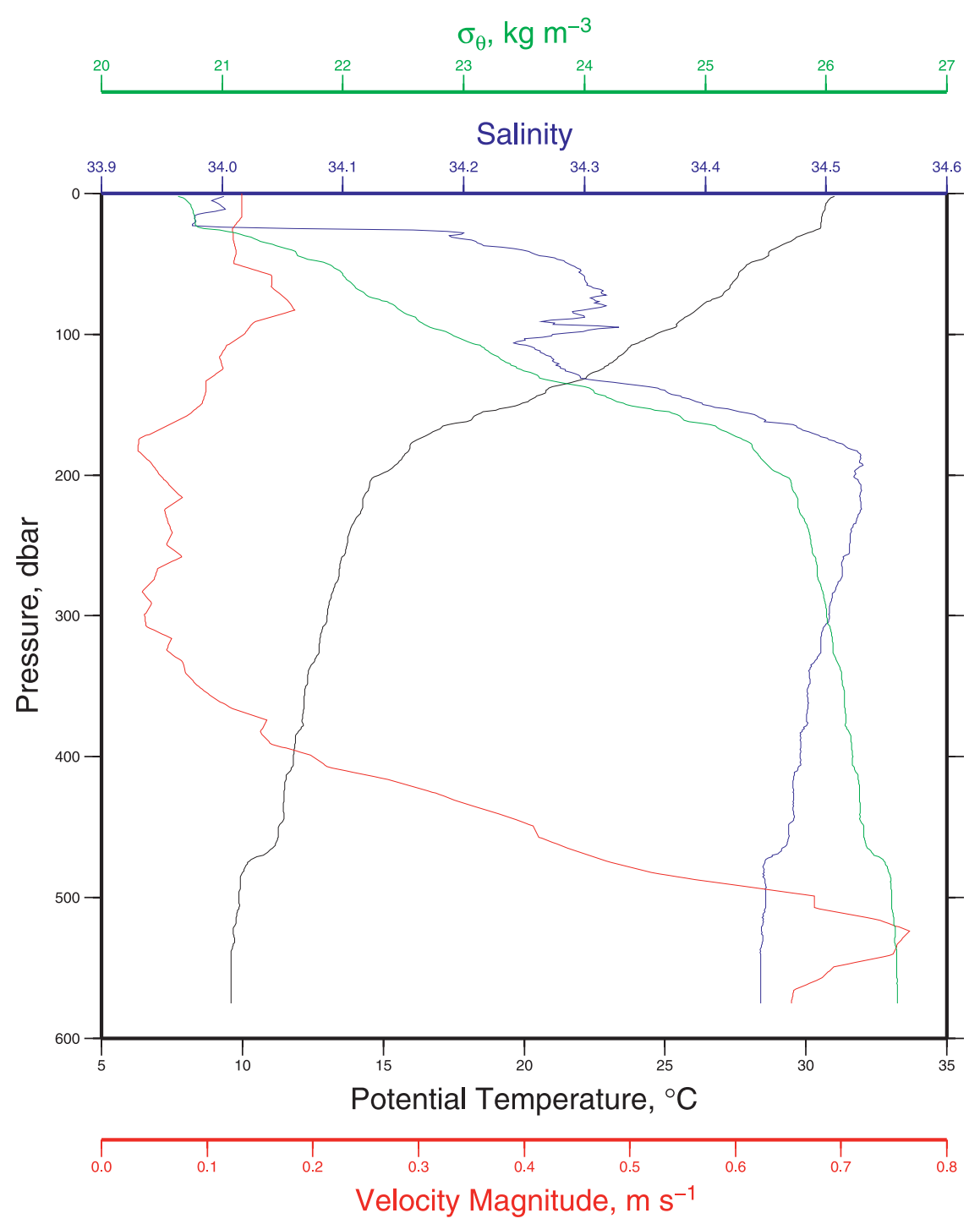

FIG. 2. Data profile for Station 8, 2007, representative of the Panay Sill mooring site, with a bottom depth of $581 \mathrm{~m}$. Flow is toward the southeast.

occupations of this station is 483 dbar (standard deviation $\sigma=15 \mathrm{dbar}$ ), with the diurnal tide the dominant source of variability (see section $3 \mathrm{~b}$ ). The overflow interface was determined by examining individual station density profiles below the thermocline for a region of increased vertical density gradient, which is explained fully in section 3c. The mean interfacial potential density $\sigma_{\theta}$ across all stations at the sill was $26.42 \mathrm{~kg} \mathrm{~m}^{-3}$. Isopycnals at the sill slope downward, coincident with the region of increased velocity (Fig. 4). Within the overflow, the mean potential temperature across the eight mooring site stations is $9.67^{\circ} \mathrm{C}\left(\sigma=0.13^{\circ} \mathrm{C}\right)$ and the mean salinity is $34.443 \mathrm{psu}(\sigma=0.003)$. Temperature and salinity characteristics are used to estimate the source of the overflow water at between approximately
380 and 440 dbar in the South China Sea. Likewise, the overflow ventilates between 800 and 1250 dbar in the Sulu Sea. These water masses are the source of the Panay Sill overflow and the region ventilated by it, respectively. Water mass modification is evident in $T-S$ space (Fig. 5), particularly between Panay Sill and the Sulu Sea. The coldest water at the sill, with potential temperature of $9.37^{\circ} \mathrm{C}$, is mixed away before reaching the Sulu Sea. Additionally, despite the loss of the freshest water in the overflow, this water remains fresher than the deep water in the Sulu Sea.

An along-channel transect of stations from 2009, in Fig. 6, shows the evolution of the overflow water salinity and dissolved oxygen from Panay Sill into the Sulu Sea. Close to the sill, bottom water retains the low-salinity 


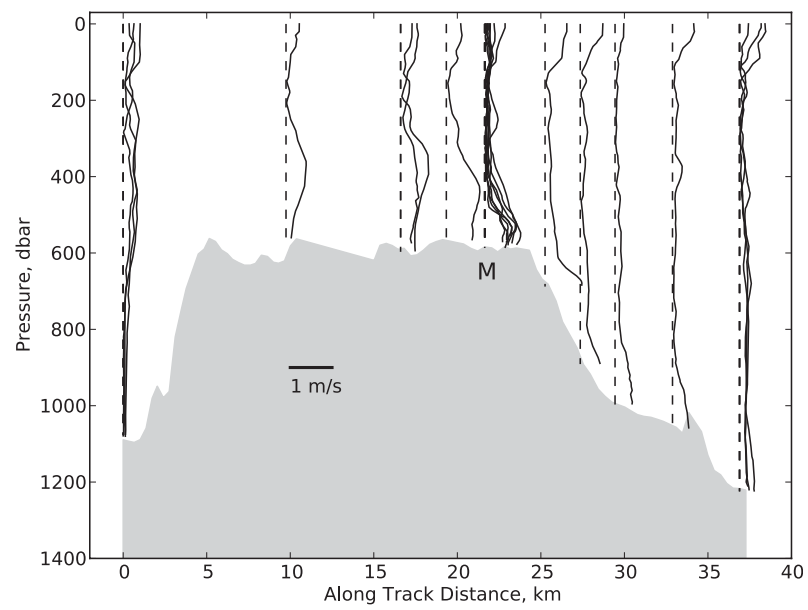

FIG. 3. Velocity magnitude profiles from LADCP data at all occupied sill region stations during 2007, 2008, and 2009. Flow is southward, to the right, and the letter $\mathrm{m}$ indicates the ADCP mooring site.

and well-oxygenated characteristics of the overflow. As the water flows southward along the seafloor and into the Sulu Sea, this low-salinity water reaches to approximately $1250 \mathrm{~m}$ before separating from the seafloor and overlying saltier, poorly oxygenated deep Sulu Sea water. The local salinity minimum marking Panay overflow water is found at slightly shallower depths in the central Sulu Sea, near $1000 \mathrm{~m}$.

The possibility remains that some portion of Panay Sill water hugged the western boundary of the channel between the sill and the Sulu Sea more closely than our sampling strategy allowed us to observe. However, the plume of overflow water stretching into the Sulu Sea matching the water characteristics observed at the sill suggests that we have, in fact, observed the dominant mass of water ventilating the intermediate depths of the Sulu Sea.

In the deep Sulu Sea, salinities reach greater than 34.47 and potential temperatures are between $9.89^{\circ}$ and $9.90^{\circ} \mathrm{C}$. Panay Sill water of this salinity is much warmer: approximately $12^{\circ} \mathrm{C}$ (Fig. 5). The source of deeper Sulu Sea water is most likely the Sulawesi Sea (Celebes Sea) to the south of the Sulu Sea. Despite the shallow sill, at $340 \mathrm{~m}$, separating the basins, high-salinity subthermocline Sulawesi Sea water is lifted over the shallow Sibutu Passage sill during extreme tide events (Gordon and Tessler 2009). Intermediate depths in the Sulu Sea are composed of a mixture of these two end-member water masses.

\section{b. Velocity observations and transport}

The along-channel velocity time series from the ADCP mooring at the sill during the three cruise periods are shown in Fig. 7. The along-channel direction (heading

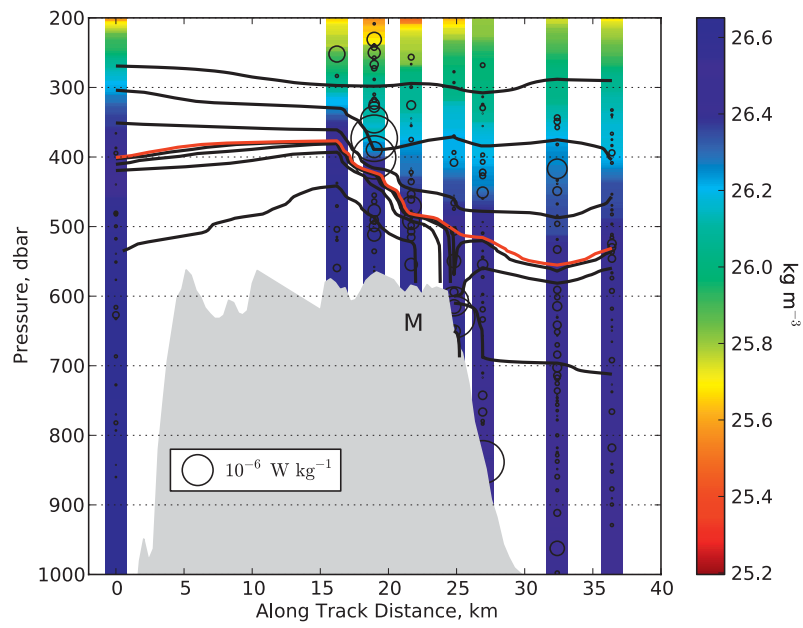

FIG. 4. Potential density $\sigma_{\theta}$ section across-sill. Stations were occupied during the 2008 channel transect. Isopycnals near the interface slope downward across the sill. The $\sigma_{\theta}=26.427$ and $26.443 \mathrm{~kg} \mathrm{~m}^{-3}$ isopycnals show a rebound immediately downstream of the sill, characteristic of a hydraulic jump. The red contour marks the $\sigma_{\theta}=26.42 \mathrm{~kg} \mathrm{~m}^{-3}$ isopycnal at the overflow interface. Each circle represents one identified overturn, and the area of the circles are proportional to the calculated turbulent dissipation rate $\epsilon$. Estimates of $\epsilon$ for individual overturns are associated with large uncertainty, though evidence of bottom-intensified mixing is clear.

$140^{\circ}$ ) was determined by the direction of flow at $520 \mathrm{~m}$, the depth of greatest mean velocity magnitude using the complete 18 -month time series. The overflow variability is clearly dominated by the diurnal tide. The general

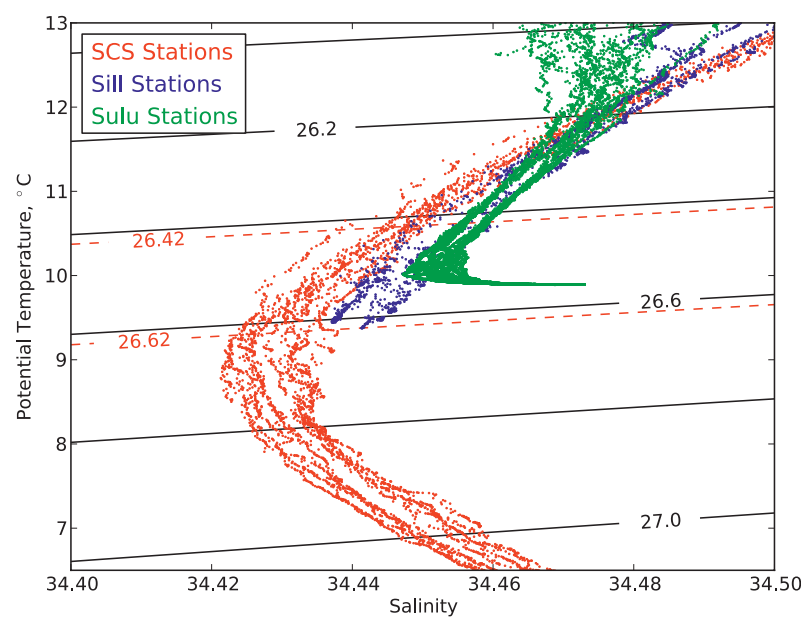

FIG. 5. A $T-S$ diagram showing the South China Sea stations (red), Panay Sill stations (blue), and Sulu Sea stations (green). See Fig. 1 for corresponding station locations. Red isopycnals identify the upper and lower bounds of the Panay Sill overflow water. Flow of water is from the South China Sea, over Panay Sill, and into the Sulu Sea. Water modification at the sill results in the loss of the coolest, freshest water because of diapycnal mixing. 

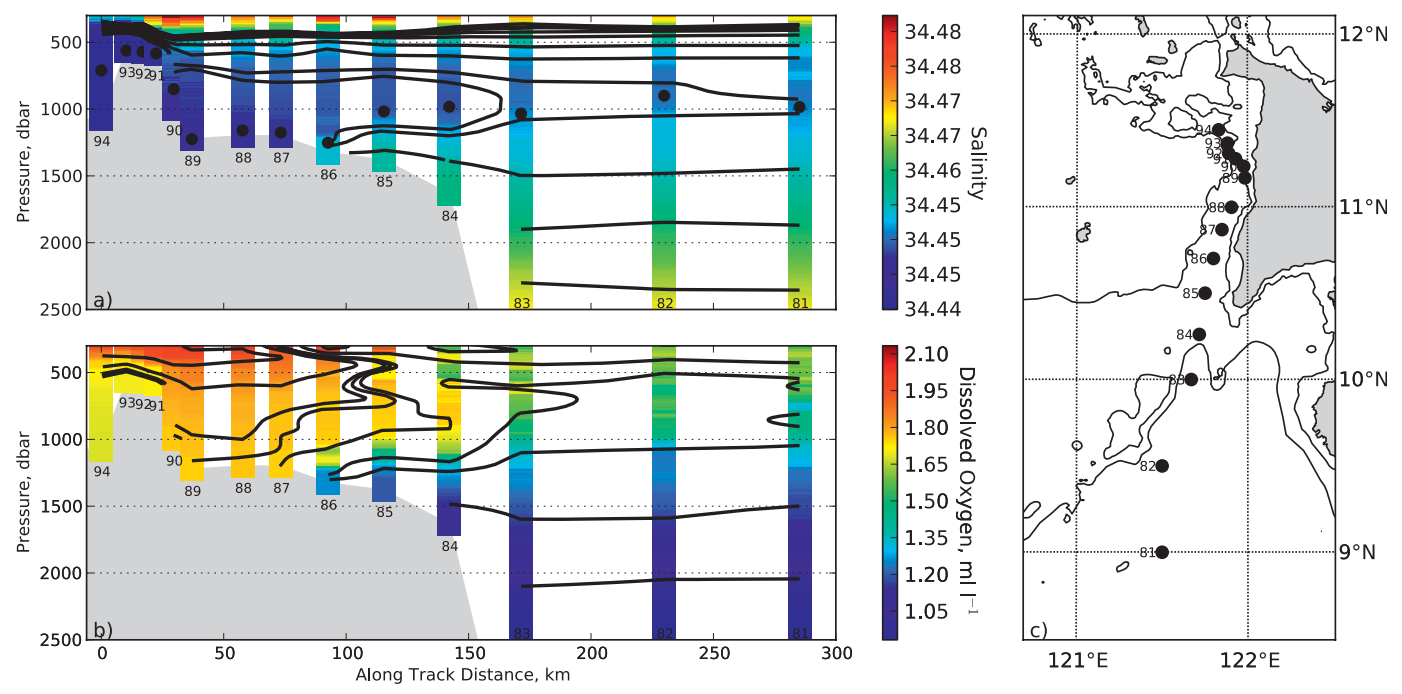

FIG. 6. (a) Salinity and (b) dissolved oxygen cross sections between the Panay Sill and the central Sulu Sea, 2009. Low salinity, oxygenated water from the sill reaches depths of approximately $1250 \mathrm{~m}$, settling above high salinity, poorly oxygenated water, which must derive from a second ventilation source. Black dots in (a) indicate local salinity minima. Station numbers correspond to the map in (c) on which contours at 500 and $2000 \mathrm{~m}$ are drawn. Note that the contour interval is uneven in (a),(b).

structure of the flow confirms the LADCP data at the sill (Fig. 3). The velocity is strongest approximately $50 \mathrm{~m}$ above the bottom with strong vertical shear between 350 and $550 \mathrm{~m}$. Also evident is a vertical migration of the interface with the diurnal tide.

Despite the relatively low latitude of the sill, $11.3^{\circ} \mathrm{N}$, dense overflow water appears banked against the right of the channel, consistent with that expected due to rotation (Fig. 8). Velocity structure is similar with elevated velocities banked to the right. The importance of rotation is addressed below with regards to hydraulic control. Velocity drops off toward the bottom of the channel, likely because of bottom friction.

To determine the transport over the sill from the single-point mooring time series we make a number of assumptions about the cross-channel structure of the overflow. First, we use the cross-channel LADCP transect to estimate the horizontal width of the overflow. Visual inspection of the zero crossings in the downstream flow above the high-velocity core suggests a width of approximately $15 \mathrm{~km}$. This estimate is subject both to spatial uncertainty regarding the flow between the stations as well as temporal uncertainty due to unresolved tidal variability. Additionally, for the velocity integration we assume the flow to be symmetrical across the sill, thus overestimating the flow to the east of the mooring and underestimating it to the west. Velocity is considered to be zero at the flow margins and scale linearly out from the mooring in the center of the channel.
As we are interested in the strength of the overflow and not the total Mindoro/Panay Strait throughflow, we do not integrate flow through the whole water column for our transport calculation. We also wish to isolate the overflow for comparison with hydraulic control theory estimates of the transport, which assumes a dense overflow with quiescent water above. While the overflow interface is well defined in potential density, temperature, and salinity, the velocity interface is less clear, particularly with regard to the strong seasonality at mid depths (Fig. 7). To separate the dense overflow from the seasonally variable and less dense flow higher in the water column we calculate the first three empirical orthogonal functions, which contain $98.3 \%$ of the total variance in the mooring time series. The leading EOF contains $89.6 \%$ of the variance and represents the dense overflow (Fig. 9). Examination of the associated principal components (PCs) shows that the leading EOF represents the bottom overflow layer and is positive throughout the time series. The second and third leading EOFs, associated with structure in the upper water column, have more pronounced seasonality that varies in sign (not shown). The second PC increases in amplitude during the autumn and winter, and the third PC shows a maximum in winter and minimum in summer. Using these results, we define the top of the overflow by the zero crossing of the leading EOF, at $408 \mathrm{~m}$ (Fig. 9).

The mean transport throughout the full time series was $0.32 \mathrm{~Sv}(\sigma=0.13 \mathrm{~Sv})$ : the mean transports during the three cruise periods are shown in Table 1 . The 


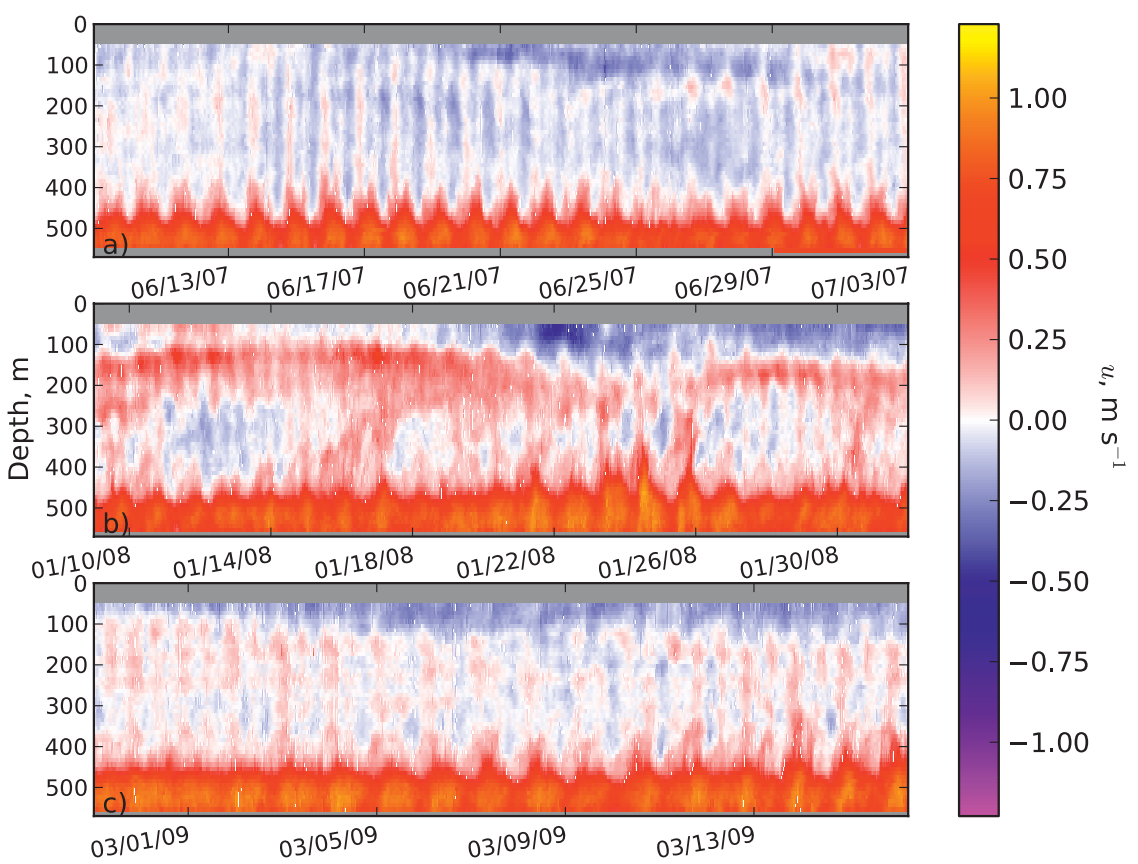

FIG. 7. Moored ADCP time series during (a) June 2007, (b) January 2008, and (c) March 2009. Velocity is positive in the downstream along-channel direction.

weakest flow (0.24 Sv) was measured during the June 2007 cruise, while the strongest was during March 2009 $(0.35 \mathrm{~Sv})$. The transport was found to be moderately sensitive to the choice of channel width. Assuming a channel width of $10 \mathrm{~km}$ resulted in a mean transport over the full time series of $0.27 \mathrm{~Sv}(\sigma=0.10 \mathrm{~Sv})$ and for a $20-\mathrm{km}$ channel width the mean transport was $0.35 \mathrm{~Sv}$ $(\sigma=0.14 \mathrm{~Sv})$.

\section{c. Hydraulic control}

A second method to estimate the transport across the sill is hydraulic control theory. At its most basic, this theory describes the physics of a fluid spilling over a weir. With rotation and stratification included, it has been applied to atmospheric and oceanic geophysical problems, including the spillage of dense water through
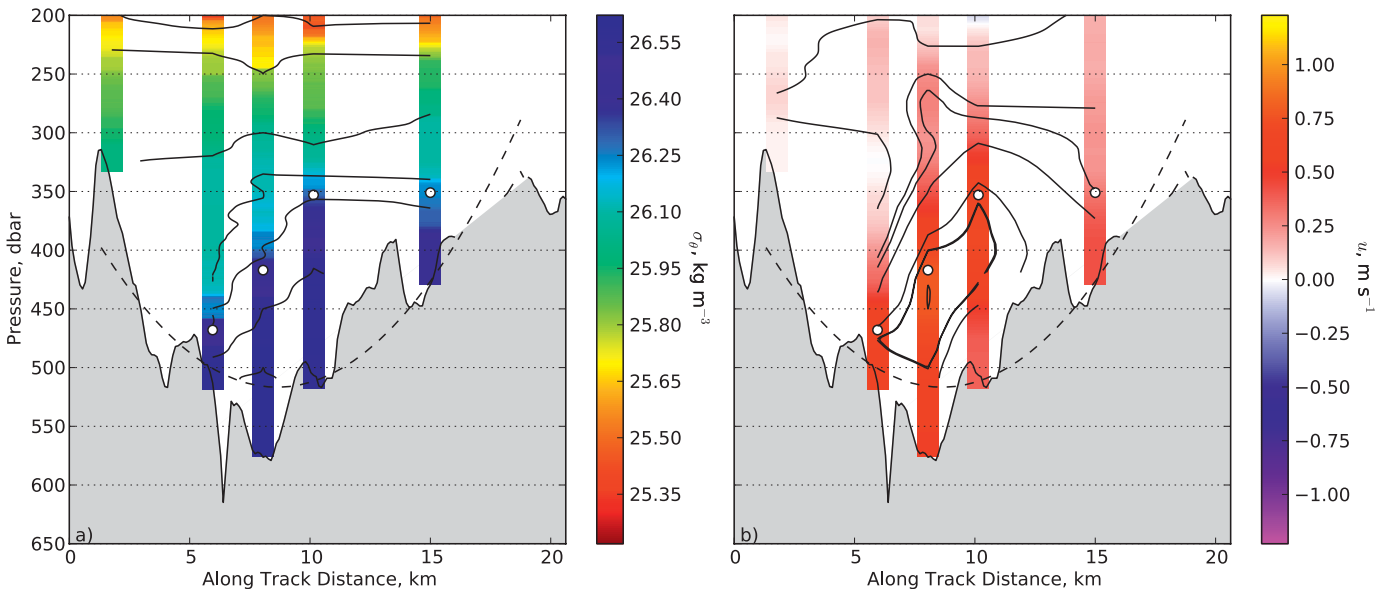

FIG. 8. CTD/LADCP sections across Panay Sill, in 2008, of (a) potential density $\sigma_{\theta}$ and (b) velocity $u$, positive downstream in the along-channel direction. The $x$ axis is oriented such that the overflow is into the paper with Panay Island to the left of the plot. The central station is $2.5 \mathrm{~km}$ upstream from the mooring site, also located in the center of the channel. Dotted line is the best-fit parabola to the bottom topography. White dots are the depths of the overflow interface identified using the potential temperature procedure described in the text. The parameter $h_{0}$ is the elevation of the interface at the central station over the seafloor. 


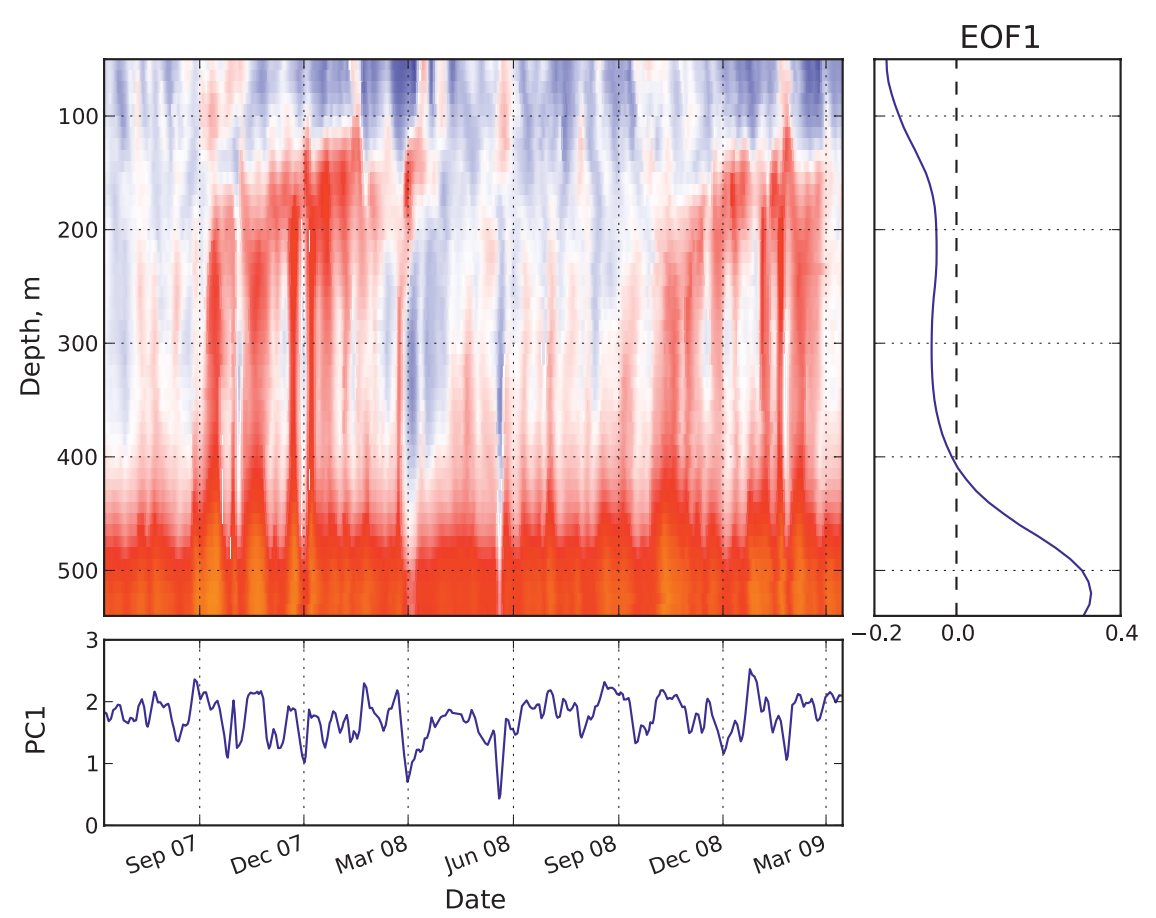

FIG. 9. The ADCP mooring time series and its leading empirical orthogonal function and principal component; EOF1 contains $89.6 \%$ of the total variance.

Denmark Strait and the Faroe Bank Channel to form North Atlantic Deep Water (Pratt and Whitehead 2008). We use a formulation of the theory assuming parabolic sill geometry and a zero potential vorticity flow based on work by Borenäs and Lundberg $(1986,1988)$. Zero potential vorticity flow would develop from water exiting a deep, still, upstream basin: the validity of this assumption is discussed below. We assume a 1.5-layer system consisting of a deep overflow and a quiescent upper layer. The definition sketch in Fig. 10 shows the channel cross section at the sill. This cross section is located at a channel depth minimum such that the bottom of the sill is a bathymetric saddle point. The coordinate system origin is located at this saddle point with $x$ in the cross-channel direction and $y$ along channel. Semigeostrophic, zero potential vorticity flow through a parabolic channel leads to a depth profile, $h$, of

$$
h(x)=\frac{1}{2}\left(1+2 r^{-1}\right)(a+x)(b-x)
$$

and a velocity profile, $v$, of

$$
v(x)=-\left[x+\frac{1}{2}\left(1+2 r^{-1}\right)(a-b)\right]
$$

where $g^{\prime}$ is the reduced gravity across the interface, $\alpha$ is the curvature of the channel at the sill, $r=f^{2} / g^{\prime} \alpha$, and $-a$ and $b$ are the two $x$ coordinates where the interface intersects the bottom such that $h(x)=0$. The Coriolis parameter $f$ is calculated at the latitude of the sill, $11.3^{\circ} \mathrm{N}$.

Insight into the effect of the sill geometry on the transport is provided by the nondimensional width $r$, which can alternatively be written as

$$
r=\frac{w_{p}^{2}}{g^{\prime} \alpha w_{p}^{2} / f^{2}}
$$

in which $w_{p}$ is the half-width of the channel when filled to an arbitrary depth $d_{p}=\alpha w_{p}^{2}$. At this depth the local Rossby radius of deformation is $\left(g^{\prime} d_{p}\right)^{1 / 2} / f=\left(g^{\prime} \alpha w_{p}^{2} /\right.$ $\left.f^{2}\right)^{1 / 2}$. Thus, $r$ is a ratio between the square of two lengths: the channel's half-width $w_{p}$ and the local Rossby radius of deformation based on the associated depth, $d_{p}$.

TABLE 1. Mean overflow volume flux and standard deviation across Panay Sill during the three cruises, derived from integrated ADCP velocity observations.

\begin{tabular}{lcc}
\hline \hline & Mean (Sv) & Std dev (Sv) \\
\hline Full & 0.32 & 0.13 \\
Jun 2007 & 0.24 & 0.08 \\
Jan 2008 & 0.32 & 0.09 \\
Mar 2009 & 0.35 & 0.07 \\
\hline
\end{tabular}




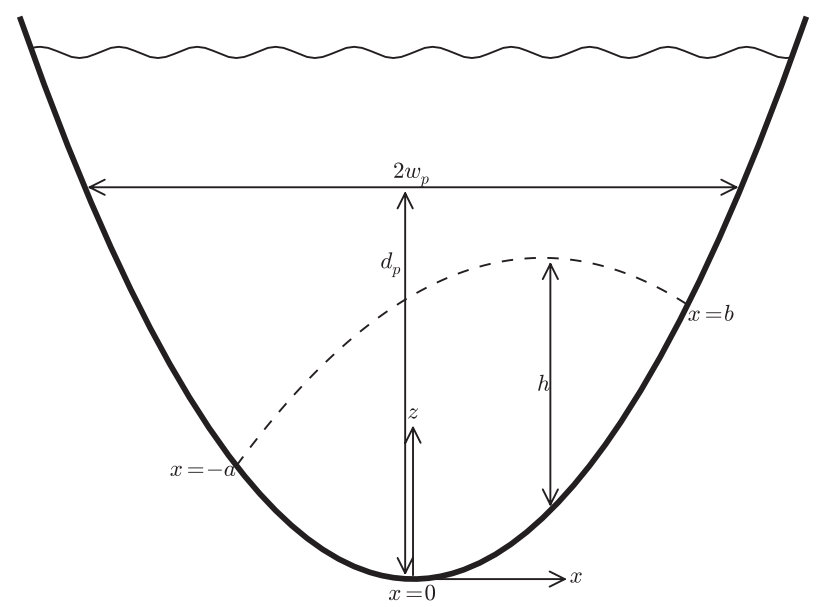

FIG. 10. Sketch of the parabolic sill geometry. The along-sill direction is taken as $x$ and the along-channel direction (into the paper, not shown), is $y$. This cross section is located at the alongchannel depth minimum, thus the coordinate system origin is a saddle point. The dotted line marks the interface between the overflow and the quiescent overlying water, which intersects the seafloor at $x=-a$ and $x=b$. The thickness of the overflow layer is $h(x)$. As noted in the text, $h_{0} \equiv h(x=0, y=0)$ at the saddle point.

At small $r$ the channel can be considered dynamically narrow, while large $r$ signifies a dynamically wide sill. Conveniently, since the parameter $r$ need not be a function of either $w_{p}$ or $d_{p}$, the transport can be determined without specifying an exact channel width.

Based on our determination of $g^{\prime}$ at each of the sill mooring stations, described in detail below, we find a mean value $r=0.18(\sigma=0.04)$; Panay Sill is dynamically narrow. The local Rossby radius of deformation based on the thickness of the overflow is approximately $16 \mathrm{~km}$, comparable to the observed overflow width. Pratt et al. (2008) investigated the stability of hydraulically controlled flows and found that while zero potential vorticity flow through a parabolic channel is always unstable, the instability is weak for $r \leq O(1)$. This suggests that flow instability may not be an important process at Panay Sill.

Hydraulic estimates of the volume flux $Q$ are based on the assumption that the flow is critical, such that

$$
6(a-b)^{2}=r(a+b)^{2}
$$

at the sill (Pratt and Whitehead 2008). Use of this condition leads to

$$
Q=\int_{-a}^{b}(v h) \mathrm{d} x=\frac{g^{\prime}(1-\gamma)(1+\gamma)^{3}}{3 r f\left(1+\frac{2}{r}\right) \gamma^{2}} h_{0}^{2},
$$

where

$$
\gamma=\frac{\sqrt{6 / r}-1}{\sqrt{6 / r}+1}
$$

and $h_{0} \equiv h(x=0, y=0)$ is the layer thickness measured at the bathymetric saddle point.

The standard practice (e.g., Borenäs and Lundberg 1988) is to invoke conservation of the volume flux and the Bernoulli function along the path of the flow so as to write $h_{0}$ in terms of layer thickness measured far upstream where the flow is assumed to be quiescent. Modeling results (Helfrich and Pratt 2003) have suggested that the Bernoulli function may not be conserved and, indeed, the procedure fails to yield good agreement with our direct estimates of transport. We have therefore opted to make an entirely local estimate, based on (5), with $\alpha, g^{\prime}, h_{0}$, etc., measured at the sill. Using a least squares polynomial fit to the multibeam bathymetry along the sill, we find the sill curvature to be $\alpha=2.23 \times$ $10^{-6}$. Calculation of $g^{\prime}$ and $h_{0}$ first requires location of the density interface in the observed sill profiles.

Temperature is the dominant control on density below the thermocline in Mindoro Strait (e.g., Fig. 2) and was used to identify the interface between the overflow and the overlying water. The interface was defined to be at the depth of the greatest potential temperature gradient deeper than $350 \mathrm{~m}$ after low-pass filtering the potential temperature. A 50-db low-pass Hanning filter was applied to the potential temperature profile before calculating the gradients because some stations showed staircase-like features above the interface that resulted in false identification of the interface. Visual inspection of the profiles confirmed that the filtering procedure identified the correct interface. The bottom depth was determined using LADCP bottom-tracking techniques (Visbeck 2002). The echo amplitude of an LADCP ping off the seafloor is significantly greater than the echoes from scatterers in the water column, allowing the location of the bottom to be determined either from dedicated "bottom-tracking" pings or regular water pings. The thickness of the overflow at the center of the sill, $h_{0}$, was then calculated as the difference between the interface depth and the bottom depth.

Calculation of the value $g^{\prime}$ is subtle because the interfacial density jump is bordered above and below by fluid that has continuous, though slight, stratification. The existence of the latter calls into question the 1.5layer approximation upon which the flux equation (5) (and most other results from rotating hydraulic theory) is based. In appendix A, we attempt to clarify this issue through reference to an idealized flow with a homogeneous lower layer flowing under a continuously stratified region, the two separated by a density interface. We discuss conditions under which the effects of the overlying 
TABLE 2. Hydraulic control results for each CTD station at the sill mooring site: $g^{\prime}$ is reduced gravity, $r$ a measure of dynamic width, $h_{0}$ the overflow thickness at the center of the sill, and $Q$ the calculated volume flux over the sill.

\begin{tabular}{lcccrc}
\hline \hline \multicolumn{1}{c}{ Date } & Station & $g^{\prime}$ & $r$ & $h_{0}(\mathrm{~m})$ & $Q(\mathrm{~Sv})$ \\
\hline 8 Jun 2007 & 8 & 0.0022 & 0.17 & 112 & 0.42 \\
9 Jun 2007 & 12 & 0.0015 & 0.25 & 88 & 0.21 \\
25 Jun 2007 & 102 & 0.0028 & 0.13 & 74 & 0.21 \\
27 Jun 2007 & 109 & 0.0025 & 0.15 & 115 & 0.47 \\
27 Jun 2007 & 112 & 0.0023 & 0.16 & 94 & 0.31 \\
27 Jun 2007 & 115 & 0.0022 & 0.17 & 84 & 0.23 \\
23 Jan 2008 & 110 & 0.0018 & 0.20 & 106 & 0.34 \\
15 Mar 2009 & 91 & 0.0015 & 0.24 & 120 & 0.40 \\
\hline
\end{tabular}

stratification can be ignored and the value of $g^{\prime}$ can be calculated solely from the density jump across the interface, as in 1.5-layer dynamics. One such circumstance applies when the flow is hydraulically critical. Since our hydraulic analysis is based entirely on the presumptively critical flow at the sill, the 1.5-layer approximation appears to be justified. Appendix A also spells out some cautions regarding more general use of this assumption.

To calculate the density jump across the interface we first identified the thermocline bottom depth as the depth that maximizes the difference between the mean overlying and mean underlying potential temperature gradients. For station 8 in 2007, Fig. 2, this depth is at 177 dbar. We then calculated the mean potential temperature gradient between the bottom of the thermocline and the seafloor. Having identified the interface using the filtered potential density gradient as described above, we searched above and below the interface for the nearest depth in each direction where the potential temperature gradient was less than the mean subthermocline gradient. These two depths defined the above and below extremes of the interface layer, and the density at these depths were used for calculation of $g^{\prime}$. Validation of this method by comparing the interfacial modes calculated for an idealized stratification with the long-wave speeds propagating along the interface is presented in appendix A.

For each CTD profile taken at the sill mooring site, $g^{\prime}$ and $h_{0}$ were calculated and used in (5) to determine the transport $Q$. The mean transport was found to be $0.32 \mathrm{~Sv}$ $(\sigma=0.1 \mathrm{~Sv})$, the same value determined from the direct integration of the moored ADCP velocity. The full results for each station are in Table 2. Although six of the eight profiles were done in June 2007, with one each in January 2008 and March 2009, the calculated transports in 2008 and 2009 are within the range of the 2007 data. The variability in the transport $Q$ is due to variability in the observed thickness of the overflow, $h_{0}$, and in reduced gravity $g^{\prime}$, resulting from changes in the density structure across the interface. However, $Q$ is most sensitive to changes in $h_{0}$. While we do not have a temperature profile time series at the sill to directly measure changes in interface depth, velocity profiles show vertical tidal migrations in addition to changes in flow velocity, suggesting the tidal variability in $h_{0}$ is the dominant source of variability in the calculated transport.

\section{Panay Sill overflow dynamics}

In January 2008 a north-south station transect was completed across the sill. With this series of hydrographic and current profiles, plus additional profiles sampled in 2007 and 2009, we can examine how dynamic properties of the flow vary from upstream to downstream of the sill. We first address the hydraulic criticality of the flow and determine locations of critical control. Second, we use Thorpe-scale overturning lengths to estimate the spatial variation of turbulence-dissipation rates across the sill.

\section{a. Flow criticality}

It is difficult to verify in a precise manner that the flow undergoes the classical subcritical-to-supercritical transition at or near the sill. The cross-stream structure is one complication; the presence of overlying stratification is another. Nevertheless, we have made a crude estimate of hydraulic criticality at various sections by calculating a Froude number Fr $=U / \sqrt{g^{\prime} h}$ based on the depth-averaged velocity $U$ near the middle of each section and the value of $g^{\prime}$ as calculated in section $3 \mathrm{c}$. The flow is subcritical $(\mathrm{Fr}<1)$ over the upstream half of the sill, becoming critical or supercritical toward the downstream end of the sill (Fig. 11). As the seafloor descends downstream of the sill, Fr drops to subcritical values. The maximum Fr value was observed at the sill mooring site, the most frequently sampled location, with values ranging from 0.7 to 1.8 , and a mean of 1.3 $(\sigma=0.4)$. Downstream of the supercritical to subcritical transition we find Fr values between 0.1 and 0.3 , though the interface is less well defined in this region and these measurements are more sensitive to changes in our working definition of the interface location and reduced gravity. Additionally, the transition from supercritical to subcritical flow is often associated with a hydraulic jump (Pratt 1983; Pratt and Armi 1987). We would therefore expect to find elevated mixing in this region. Gradient Richardson numbers, $\mathrm{Ri}=N^{2} /(d U / d z)^{2}$, less than $1 / 4$ are found within the overflow, indicating the potential for turbulent mixing due to shear instabilities (Fig. 12). 


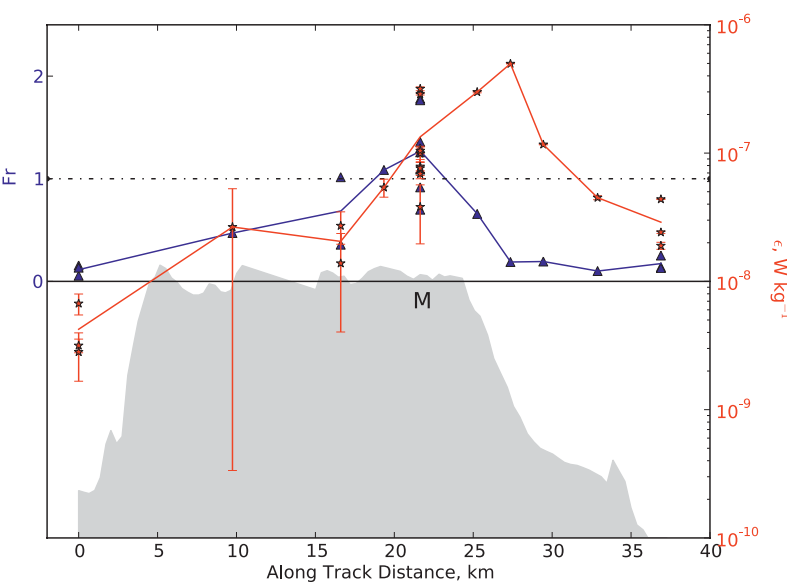

FIG. 11. Evolution across the sill of the Froude number Fr (blue) and mean rate of loss of turbulent kinetic energy $\epsilon$ within the overflow (red). Dissipation rate $\epsilon$ values are midpoints between upper and lower bounds, as described in the text. Symbols indicate estimates at individual stations, lines connect averages where repeat stations are available. Flow is to the right; "M" indicates the ADCP mooring site.

\section{b. Turbulence dissipation}

One approach to quantifying the dissipation rate is to examine the length scales of density overturns. The relevance of this scale, called the Thorpe scale (Thorpe 1977), builds on the assumption of a stably stratified background density profile perturbed by turbulent mixing. These perturbations move dense water over lighter water, resulting in density inversions in the measured profile. Details of density overturn identification, calculation of Thorpe scales, and estimation of turbulence-dissipation rates for individual overturns are in appendix B.

The mean dissipation rate within the overflow, shown in Fig. 11, was calculated as

$$
\epsilon=\frac{1}{H} \sum_{i} \epsilon_{i} h_{i}
$$

where $H$ is the thickness of the overflow layer and $\epsilon_{i}$ and $h_{i}$ are the dissipation rate and thickness of individual overturns within the overflow layer. With 1-dbar resolution data, the minimum resolvable overturn thickness is $2 \mathrm{dbar}$, with a corresponding $L_{T}=1 \mathrm{dbar}$. In addition to observed overturns, presumably there are unresolvable density inversions in the water column with $L_{T}<1$ dbar. We can put upper and lower bounds on the dissipation rate estimates by making different assumptions about the subresolution-scale overturning. The dissipation rate for an individual overturn of $L_{T}=1 \mathrm{dbar}$ varies with the background stratification; within the sill overflow we find it ranges from $2 \times 10^{-9}$ to $9 \times 10^{-8} \mathrm{~W} \mathrm{~kg}^{-1}$, with a mean of approximately $4 \times 10^{-8}$.

At each station, we can estimate a lower bound for the mean dissipation rate by assuming depths with no

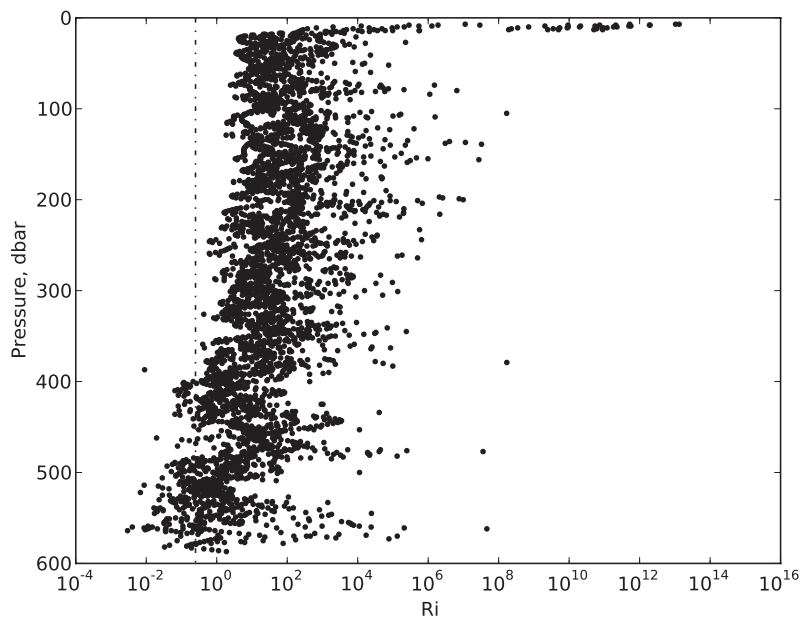

FIG. 12. Gradient Richardson numbers, calculated using a 10-dbar length scale, for all stations at the sill mooring site. Below approximately $400 \mathrm{dbar}$, we find $\mathrm{Ri}<1 / 4$, indicating potential for shear instabilities.

resolvable overturns have zero dissipation. Likewise, we estimate an upper bound by assuming all depths with no resolvable overturns contain the largest possible subresolution-scale overturns. These upper and lower bounds do not constrain the dissipation estimates of observed overturns; rather they provide a limit to the amount of dissipation that occurs at subresolution scales.

Estimated dissipation rates across Panay Sill range from $3 \times 10^{-10}$ to $5 \times 10^{-7} \mathrm{~W} \mathrm{~kg}^{-1}$. A corresponding estimate of the mean eddy diffusivity is $4 \times 10^{-4} \mathrm{~m}^{2} \mathrm{~s}^{-1}$, given by

$$
K_{\rho}=\Gamma \epsilon N^{-2}
$$

in which $\Gamma$, the mixing efficiency, is taken as 0.2 , though there is theoretical and observational evidence that $\Gamma$ varies with different mixing environments; so this is likely a simplification (Ruddick and Walsh 1997; Smyth et al. 2001).

The highest dissipation rates were found on the downstream side of the sill where the bottom slope increased. Upstream stations at the sill contain fewer and smaller observed overturns and more of the depth profile is subject to uncertainty at the $L_{T}<1$-dbar scale. Downstream station profiles contain larger overturns that dominate the dissipation rate average. Additionally, these large overturns leave less of the profile subject to subresolutionscale overturning, reducing the range between the upper and lower bounds. The calculated dissipation rates for individual overturns tend to be highly uncertain and the absolute magnitudes are not discussed in detail, though the spatial distribution shown in Fig. 4 is similar to the patterns seen in the mean overflow dissipation rates. 
Elevated turbulent mixing associated with sill overflows has also been observed elsewhere, including in the Romanche Fracture Zone (Polzin et al. 1996) and Mid-Atlantic Ridge canyons (Thurnherr 2006).

That the dissipation rate in the overflow reaches high values in the range of $10^{-7}$ to $10^{-6} \mathrm{~W} \mathrm{~kg}^{-1}$ immediately downstream of where the Froude numbers show the flow transitions from supercritical to subcritical suggests that there is a hydraulic jump on the downstream slope of Panay Sill. Downward sloping isopycnals across the sill show an upward rebound here as well, consistent with a hydraulic jump (Fig. 4). Strong mixing downstream of a hydraulic control point is consistent with observations at sills along the Mid-Atlantic Ridge by Thurnherr et al. (2002).

Despite significant turbulent mixing in the overflow layer, a weak background stratification is evident in density profiles at the sill (Fig. 2). The maintenance of this weak stratification requires a buoyancy flux across the upper interface of the overflow. A control volume approach can be used to estimate this diapycnal buoyancy flux. We considered an along-channel control volume defined by three 2008 stations, connected by the solid red line in the inset to Fig. 1. This control volume is located at the sill, upstream of the hydraulic jump. Balancing the diffusive diapycnal buoyancy flux at the interface and the change in advected buoyancy across the volume,

$$
K_{\rho} A \frac{\partial \sigma}{\partial z}=Q \Delta \sigma
$$

where $K_{\rho}$ is the eddy diffusivity through the overflow interface approximated by the $\sigma_{\theta}=26.42 \mathrm{~kg} \mathrm{~m}^{-3}$ surface, $A=82 \mathrm{~km}^{2}$ is the area of the surface, $\partial \sigma / \partial z$ is the potential density gradient evaluated at the interface surface, $Q=0.32 \mathrm{~Sv}$ is the volume flux through the control volume, and $\Delta \sigma$ is the difference between the mean potential density at the upstream and downstream bounds of the control volume. We find the necessary eddy diffusivity $K_{\rho}$ at the overflow interface to be approximately $6 \times$ $10^{-3} \mathrm{~m}^{2} \mathrm{~s}^{-1}$. This bulk estimate at the overflow interface is an order of magnitude greater than the Thorpe-scalebased estimate within the overflow of $4 \times 10^{-4} \mathrm{~m}^{2} \mathrm{~s}^{-1}$.

\section{Discussion}

\section{a. Transport estimates}

Both the mooring time series integration and hydraulic control theory determine that an overflow transport at Panay Sill is approximately $0.3 \mathrm{~Sv}$. This conclusion is strengthened by the independence between these two measures: direct current measurements from the moored ADCP and a hydraulic control model from hydrographic data alone. One potential source of error in both estimates is the uncertainty of the width of the overflow current. The ADCP integration is sensitive to this parameter, and our best estimate of the width is based on LADCP measurements from a single cross-channel transect in 2008. How the effective width of the flow varies on tidal, seasonal, or annual time scales is uncertain. Although the parabolic hydraulic control transport estimate does not depend on channel width directly, the curvature of the channel varies on different length scales. The average sill curvature would be decreased for a wider overflow.

$\mathrm{Qu}$ and Song (2009) published estimates of Mindoro Strait transport using satellite-derived sea surface height and ocean bottom pressure measurements. Their model was based on rectangular hydraulic control theory and geostrophic control (Whitehead 1989; Garrett and Toulany 1982; Song 2006) to estimate a full-watercolumn transport of $2.4 \mathrm{~Sv}$ and a bottom-layer transport of $1.3 \mathrm{~Sv}$. Although we do not estimate the full water column transport here, our bottom layer estimates are significantly lower, 0.3 versus $1.3 \mathrm{~Sv}$. This difference most likely stems from inadequacies in the topographic and hydrographic datasets used by $\mathrm{Qu}$ and Song. For instance, compared to the observed bathymetry from the multibeam system on the R/V Melville, the Smith and Sandwell (1997) topography shows the sill to be wider and farther west from Panay Island, and the seafloor slope gentler both upstream and downstream of the sill. While their model takes accounts for bottom friction, the intense mixing observed downstream of the sill reduces the reliability of a hydraulic control model based on far upstream and downstream hydrographic profiles.

With regard to seasonal variability, we confirm the strengthening of flow during the fall observed by Qu and Song (2009), although we also found the strong seasonal velocities in the upper water column to continue through the early winter. We should also note that the sill mooring site is located approximately $2 \mathrm{~km}$ downstream from the narrowest section of the sill, where our cross-channel transect was conducted. Although the along-channel LADCP measurements suggest that the flow does not appreciably change between the narrowest section and the mooring location, if this assumption is subject to tidal or seasonal variability not captured by the LADCP measurements, then our observed transport estimates would be biased low.

\section{b. Sulu Sea ventilation}

We can estimate the residence time of the upper Sulu Sea and make bulk diapycnal mixing estimates using the mean Panay Sill transport estimate of $0.32 \mathrm{~Sv}$. Previous estimates of Sulu Sea residence time include work by Broecker et al. (1986), who used radiocarbon methods to yield a residence time upper bound estimate of 100 years, and Gamo et al. (2007), who used deep Sulu Sea 
oxygen to place a lower bound on residence time of 50 years. These estimates, however, assume that the whole water column of the Sulu Sea is ventilated by Mindoro Strait, whereas our results suggest the ventilation only occurs to approximately 1250 dbar.

The mean interfacial potential density $\sigma_{\theta}$ at the sill mooring site is $26.42 \mathrm{~kg} \mathrm{~m}^{-3}$. Downstream in the Sulu Sea this isopycnal is found at approximately $575 \mathrm{dbar}$. As the slab in the Sulu between this isopycnal at 575 and 1250 dbar is ventilated by the Panay Sill overflow, we calculate a residence time for this slab of $11 \mathrm{yr}$ based on a volume flux of $0.32 \mathrm{~Sv}$ and a slab volume of $1.1 \times 10^{14} \mathrm{~m}^{3}$.

This water must upwell across the $\sigma_{\theta}=26.42 \mathrm{~kg} \mathrm{~m}^{-3}$ surface and escape from the Sulu Sea into the South China Sea or the Sulawesi Sea. It is likely that the pathway to the South China Sea or Sulawesi Sea first involves entrance into the Bohol Sea through the 450-m-deep Dipolog Strait, with subsequent return to the Sulu at a shallower level within Dipolog Strait. Initial analysis of the Panay mooring time series reveals near-zero net transport above the overflow layer (J. Sprintall et al. 2010, unpublished manuscript), suggesting that the Panay overflow eventually exits the Sulu Sea through the Sibutu Passage into the Sulawesi Sea. After entering the Sulu Sea the Panay overflow water must upwell through the $26.42 \sigma_{\theta}$ surface. Using a similar control volume approach as at the sill, we can calculate a bulk eddy diffusivity estimate through this surface necessary to balance the buoyancy difference between incoming water from the Panay overflow and the upwelling water. From (8), where $A=$ $1.8 \times 10^{11} \mathrm{~m}^{2}$ is the area of the 575 -dbar surface in the Sulu Sea, $Q=0.32 \mathrm{~Sv}$ is the volume flux into the Sulu Sea and equivalently by mass conservation through the 575-dbar surface, $\Delta \sigma=0.14 \mathrm{~kg} \mathrm{~m}^{-3}$ is the density difference between inflowing transport-weighted Panay Sill overflow water and upwelling Sulu Sea water at $575 \mathrm{dbar}$, and $\partial \sigma / \partial z=5.6 \times 10^{-4} \mathrm{~kg} \mathrm{~m}^{-4}$ is the stratification at 575 dbar in the Sulu Sea, we obtain an eddy diffusivity estimate of $K_{\rho}=4.4 \times 10^{-4} \mathrm{~m}^{2} \mathrm{~s}^{-1}$. A similar calculation using potential temperature rather than potential density results in $K_{\rho}=4.5 \times 10^{-4} \mathrm{~m}^{2} \mathrm{~s}^{-1}$. These values, while an order of magnitude larger than nominal background mixing in the abyssal ocean (Munk 1966), are of the same order as those obtained in the South China Sea (Qu et al. 2006b), which, like the Sulu Sea, is subject to strong internal waves and solitons (Apel et al. 1985; Ramp et al. 2004).

\section{Conclusions}

Our results show evidence for a strong bottomenhanced overflow current at Panay Sill, transporting approximately $1 / 3 \mathrm{~Sv}$ from the South China Sea to the
Sulu Sea. This water does not appear to descend into the deep Sulu Sea but, rather, finds neutral buoyancy above approximately 1250 dbar. Below this depth we observe water that cannot be traced to the Panay Sill, suggesting a second ventilation source for the deep Sulu Sea. The overflow shows strong tidal variability with downstream velocities over $70 \mathrm{~cm} \mathrm{~s}^{-1}$ observed during flood tide. The flow appears to be hydraulically controlled at the sill with a likely hydraulic jump downstream of the control point. Strong turbulent mixing was observed in the overflow, with estimated turbulence dissipation rates up to $5 \times 10^{-7} \mathrm{~W} \mathrm{~kg}^{-1}$.

The Panay Sill overflow water ventilates an upper slab of the Sulu Sea between approximately 600 and 1250 dbar with an estimated residence time of 11 years. Assuming a steady state in the upper Sulu Sea, we estimate a bulk average diapycnal eddy diffusivity above this slab of $4.4 \times 10^{-4} \mathrm{~m}^{2} \mathrm{~s}^{-1}$.

Acknowledgments. This work was supported by the Office of Naval Research Grant N00014-09-1-0582 to Lamont-Doherty Earth Observatory of Columbia University; Grants ONR-13759000 and N00014-09-1-0582 to the Woods Hole Oceanographic Institution; Grant ONR-N00014-06-1-0690 to Scripps Institute of Oceanography; and a National Defense Science and Engineering Graduate Fellowship. The authors thank Andreas Thurnherr for his helpful discussions.

\section{APPENDIX A}

\section{Justification of the 1.5-Layer Approximation at the Sill}

Fitting a layer model to a flow with continuous vertical variations in velocity and stratification requires estimation of the density jump $\Delta \rho$, and a corresponding value of $g^{\prime}$, across the hypothetical interface. For the Panay Sill overflow we have attempted to model the dense overflow as the active lower layer of a 1.5-layer system with the interface corresponding to a location where the density profile undergoes a slight but rapid change in the vertical. Above the interval of rapid change the density decreases at a rate that is roughly linear in elevation for $250 \mathrm{~m}$ or so. A two-dimensional idealization (Fig. A1, left) consists of a homogeneous bottom layer overlain by an interface and, above it, a layer with constant stratification $N>0$. The bottom layer has a thickness $h$ and moves at uniform velocity $U>0$, whereas the upper fluid is quiescent. As partial justification for the 1.5-layer approximation used in this work, we examine the conditions under which the approximation is justified in this simplified two-dimensional setting. 


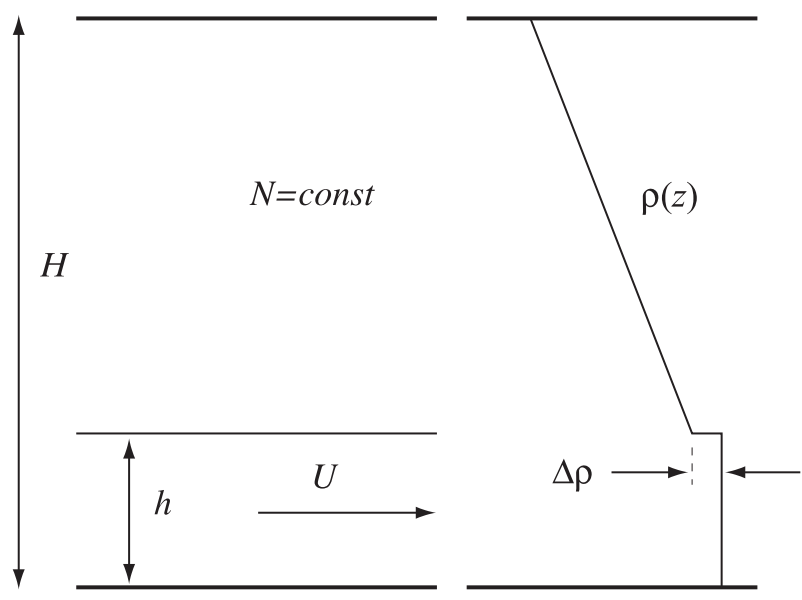

FIG. A1. Idealization of a homogeneous bottom layer overlain by an interface: above it is a layer with constant stratification $N>0$.

Conventional hydraulic theories, including those used here, assume that the upper layer is homogeneous $(N=$ $0)$ and inactive. Critical conditions, transport formulas, and other hydraulic properties then depend on the expression $U \pm\left(g^{\prime} h\right)^{1 / 2}$ for the speed of long gravity waves propagating on the interface, with $g^{\prime}$ calculated as described above. How does finite stratification in the upper fluid alter this picture? Some guidance is given by calculation of the speed of the same interfacial mode for the system with finite stratification in the upper layer. As discussed by Pratt and Whitehead (2008), waves relevant for hydraulic control are horizontally long and have a modal structure in the vertical that satisfies boundary conditions at the top and bottom. In particular, the modes are solutions of the Taylor-Goldstein equation for long waves:

$$
\frac{d^{2} \tilde{w}}{d z^{2}}+\left[\frac{N^{2}}{(U-c)^{2}}-\frac{d^{2} U}{d z^{2}}\right] \tilde{w}=0
$$

subject to the boundary and matching conditions

$$
\begin{aligned}
\tilde{w} & =0 \quad(z=0, H), \\
\left(\frac{\tilde{w}}{U-c}\right)_{z=h^{-}}^{z=h^{+}} & =0 \quad(z=h),
\end{aligned}
$$

and

$$
\left[(U-c) \frac{d \tilde{w}}{d z}-\tilde{w} \frac{d U}{d z}-\frac{g \rho}{\rho_{0}} \frac{\tilde{w}}{(U-c)}\right]_{z=h^{-}}^{z=h^{+}}=0 \quad(z=h) .
$$

Here the vertical structure of the vertical velocity is given by $w(x, z, t)=\operatorname{Re}\left[\tilde{w}(z) e^{i k(x-c t)}\right]$ and thus $\tilde{w}$ gives its vertical structure. The first matching condition from (A2) follows from the kinematic condition at the interface, whereas (A3) follows from a single integration of (A1) across the interface.

The vertical eigenfunctions for (A1)-(A4) are

$$
\tilde{w}= \begin{cases}A \sin [N(H-z) / c], & h<z<H \\ B z / h, & 0<z<h .\end{cases}
$$

The wave speed $c$ is given by the transcendental relation:

$$
(U-c)^{2}=g^{\prime} h-c N h \cot [N(H-h) / c],
$$

where $H$ is the total water depth. It will be convenient to consider the following nondimensional version,

$$
\left[\left(F_{d}-\tilde{c}\right)^{2}-1\right] \sin \left[\frac{\gamma(1-\varepsilon)}{\tilde{c}}\right]=-\varepsilon \gamma \tilde{c} \cos \left[\frac{\gamma(1-\varepsilon)}{\tilde{c}}\right]
$$

with $\tilde{c}=c /\left(g^{\prime} h\right)^{1 / 2}, F_{d}=U /\left(g^{\prime} h\right)^{1 / 2}, \gamma=N H /\left(g^{\prime} h\right)^{1 / 2}$, and $\varepsilon=h / H$. In the Panay Sill region, $\gamma \approx 4.9$ and $\varepsilon \approx 0.18$.

If the upper layer is made homogeneous $(N \rightarrow 0)$, (A6) yields the familiar wave speed $c=U \pm\left(g^{\prime} h\right)^{1 / 2}$ for a 1.5-layer system. If $U=0$ and $h \rightarrow 0$ so that the entire water column is stratified, then solutions of (A1)-(A4) obey $\cot [N H / c] \rightarrow \infty$ or $c= \pm N H / n \pi$ for $n=1,2,3 \ldots$ These are the speeds of the long internal modes under constant stratification. For our application to the Panay Sill region, the question under consideration is whether the 1.5-layer formula yields an accurate estimate of the vertical mode that is relevant for the dynamics of the overflow. There are at least two circumstances where this approximation is justified. The most obvious is when the overlying stratification is weak in the sense $\gamma \ll 1$. Then the rhs of (A6) is negligible and $c=U \pm\left(g^{\prime} h\right)^{1 / 2}$ is an approximate solution. For the Panay Sill stratification $\gamma$ is not small, and the approximation cannot be justified on these grounds.

The second circumstance is more subtle and can be revealed by setting $F_{d}=1$ in (A6). The resulting equation,

$$
\tilde{c}\left\{(\tilde{c}-2) \sin \left[\frac{\gamma(1-\varepsilon)}{\tilde{c}}\right]+\varepsilon \gamma \tilde{c} \cos \left[\frac{\gamma(1-\varepsilon)}{\tilde{c}}\right]\right\}=0,
$$

has as a solution $\tilde{c}=0$. (The sine and cosine functions in the bracketed expression oscillate rapidly but remain bounded as $\tilde{c}$ approaches zero, so the root $\tilde{c}=0$ is genuine.) Thus, the familiar critical condition $F_{d}=1$ for the 1.5-layer system implies the existence of a stationary wave mode of the more general system. Moreover, the amplitude $A$ of this mode in the overlying stratification is zero, as follows from (A5). Thus, the 
critical condition for the 1.5-layer system implies that the more general flow is also critical and that the stationary wave mode has all the characteristics of the 1.5-layer critical mode, with $g^{\prime}$ determined by the density jump across the interface. If the overflow in question passes through a point where $F_{d}=1$, then the above characteristics will hold within a certain approximation in the immediate vicinity of the point, where $F_{d}$ is approximately unity. Our hydraulic estimate of the Panay Sill volume flux is based entirely on quantities evaluated at or near the location where $F_{d}=1$ : the 1.5-layer approximation inherent in the formulas applied would appear to be justified at these locations.

This conclusion comes with several caveats. First, our use of the 1.5-layer model would not be globally justified for a hydraulic analysis that links volume flow rate to upstream conditions since the upstream typically has $F_{d} \ll 1$. Second, our justification is based on a nonrotating model of waves in a $2 \mathrm{D}$ stratified flow, whereas the flux formula is based on rotating 3D flow. Ideally, one would like to carry out the above analysis for a full 3D stratified flow, but this is well beyond the present state of the art in the field.

Ambiguities in the estimation of $g^{\prime}$ could, in principle, be avoided through calculation of the continuous vertical modes of the observed, continuously stratified shear flow. Gregg and Pratt (2010) recently did this for the flow in the Hood Canal by solving the extended TaylorGoldstein (eT-G) equation (Pratt et al. 2000), which takes the cross-sectional topography into consideration but assumes that the vertically varying velocity and density is uniform in the cross-channel direction. This approach would be more problematic at the Panay Sill where rotationally induced, cross-channel gradients are stronger than for the Hood Canal. A proper analysis involves computation of modes that are two dimensional, something that has never been done in this context. A second problem is that the overflow is confined to a small segment at the bottom of the water column and that significant variations in horizontal velocity and $N$ exist higher up. We attempted to calculate the onedimensional modes of the eT-G equation based on a single profile of $U$ and $N$ from the Panay Sill but found a large number of modes with very complicated vertical structures. We had a difficult time sorting these out and determining which were real (and not just representations of the continuous spectrum) and which were relevant to the overflow. The issues of interpretation became sufficiently complex that we attempted to simplify the upper water column by replacing the actual $U$ and $N$ with $U=0$ and $N=$ const. Of course, this is very close to the idealized model described in the manuscript, one that can be solved analytically. Given the scope of the present paper, we have opted for a simpler and more straightforward analytical approach.

The editor has also asked us to comment on the possibility that radiating waves might influence the fluid aloft, were the idealized background state (Fig. A1) forced from below by a sill or obstacle. The question is whether radiation could alter the region of uniform shear and $N$ above the obstacle and thereby change the long-wave structure. This process is certainly possible and can be seen in the atmosphere over mountain ranges, but the main alteration of the flow occurs downstream of the topographic crests. However, the uniform state that we have chosen is based on the observed structure of the flow above the sill, and we are simply asking what the long-wave modes of this flow are. These are the modes relevant for hydraulic control.

\section{APPENDIX B}

\section{Calculation of Turbulence-Dissipation Rates from Thorpe Length Scales}

The Thorpe length scale $L_{T}$ is defined as the root mean square of the vertical displacements $d$ required to resort the profile into a stable configuration:

$$
L_{T}=\bar{d}^{1 / 2}
$$

The scale $L_{T}$ is calculated for each overturn in the profile using a procedure described below.

An additional length scale, relevant in turbulent water, is the Ozmidov scale $L_{O}$,

$$
L_{O}=\epsilon^{1 / 2} N^{-3 / 2},
$$

where $\epsilon$ is the dissipation rate of turbulent kinetic energy and $N$ is the Brunt-Väisälä frequency. The scale $L_{O}$ relates the scale of the largest eddies possible in a water column with a stable background stratification. This is valid when the scale of turbulent motions is large enough that viscosity is very small and energy dissipation and stratification are the only relevant dimensional quantities (Thorpe 2005). Setting $l=L_{O} / L_{T}$ we obtain the dissipation $\epsilon$ as a function of $L_{T}$,

$$
\epsilon=l^{2} L_{T}^{2} N^{3}
$$

The linear relationship between $L_{O}$ and $L_{T}$ has been shown to be valid in a range of environments (Dillon 1982; Wesson and Gregg 1994; Moum 1996; Ferron et al. 
1998), with $l$ estimated between 0.65 and 0.95 . Here we use $l=0.80$ from Dillon (1982), whose results were shown to hold under a range of different oceanic mixing conditions.

To determine the spatial distribution of turbulence in the Panay Sill overflow, we first identified all overturns in the Panay Sill CTD profiles. The downcast profiles were processed to $1-\mathrm{db}$ resolution. Potential temperature data were used to identify the overturns because temperature is the dominant determinant of density at the sill. Additionally, the temperature sensor used has a lower noise level than the conductivity sensor. However, results obtained using $\sigma_{\theta}$ to identify overturns were very similar. Based on visual inspection of temperature profiles in the deep Sulu Sea where stratification is very weak, we find the noise level for the temperature sensor to be $5 \times 10^{-4}{ }^{\circ} \mathrm{C}$. The noise level was consistent across all three cruises. The noise level must be accounted for in the overturn identification procedure to avoid introducing spurious overturns and upward biasing of the dissipation rate estimates. We use the procedure developed by Thorpe (1977) of rejecting any overturn where the sorted profile differs from the original profile by less than the noise level. Other schemes have been developed, though this method has been shown to be reliable (Ferron et al. 1998; Thurnherr et al. 2002).

Our procedure to locate overturns begins by calculating the Thorpe displacements $d_{i}$, the difference of the sorted depth of each sample from the original depth. We then searched from the surface to the bottom for nonzero values of $d_{i}$, which indicated the beginning of an overturn. When the cumulative sum of the displacements in an overturn $\sum_{i} d_{i}$ equaled 0 , the overturn was considered complete. Each overturn was then checked for rejection based on the noise level. The Thorpe scale $L_{T}$ and $\epsilon$ were calculated for the true overturns using Eqs. (B1) and (B3), taking $\mathrm{N}$ as the stratification of the sorted profiles and therefore always real. On the downstream side of the sill, $L_{T}$ scales up to $38 \mathrm{~m}$ were observed within the overflow.

\section{REFERENCES}

Apel, J., J. Holbrook, A. Liu, and J. Tsai, 1985: The Sulu Sea internal soliton experiment. J. Phys. Oceanogr., 15, 1625-1651.

Borenäs, K., and P. Lundberg, 1986: Rotating hydraulics of flow in a parabolic channel. J. Fluid Mech., 167, 309-326.

—, and — 1988: On the deep-water flow though the Faroe Bank Channel. J. Geophys. Res., 93 (C2), 1281-1292.

Broecker, W. S., W. C. Patzert, J. R. Toggweiler, and M. Stuiver, 1986: Hydrography, chemistry, and radioisotopes in the Southeast Asian basins. J. Geophys. Res., 91 (C12), 14 345-14 354.

Chao, S., P. Shaw, and S. Wu, 1996: Deep water ventilation in the South China Sea. Deep-Sea Res., 43, 445-466.
Dannenmann, S., B. K. Linsley, D. W. Oppo, Y. Rosenthal, and L. Beaufort, 2003: East Asian monsoon forcing of suborbital variability in the Sulu Sea during Marine Isotope Stage 3: Link to Northern Hemisphere climate. Geochem. Geophys. Geosyst., 4, 1001, doi:10.1029/2002GC000390.

Dillon, T. M., 1982: Vertical overturns: A comparison of Thorpe and Ozmidov length scales. J. Geophys. Res., 87 (C12), 96019613.

Ferron, B., H. Mercier, K. Speer, A. Gargett, and K. Polzin, 1998: Mixing in the Romanche Fracture Zone. J. Phys. Oceanogr., 28, 1929-1945.

Gamo, T., Y. Kato, H. Hasumoto, H. Kadiuchi, N. Momoshima, N. Takahata, and Y. Sano, 2007: Geochemical implications for the mechanism of deep convection in a semi-closed tropical marginal basin: Sulu Sea. Deep-Sea Res., 54, 4-13, doi:10.1016/ j.dsr2.2006.06.004.

Garrett, C., and B. Toulany, 1982: Sea level variability due to meteorological forcing in the northeast Gulf of St. Lawrence. J. Geophys. Res., 87, 1968-1978.

Gordon, A., and Z. Tessler, 2009: Competing overflows into the deep Sulu Sea. Proc. MOCA-09, Montreal, Canada, IAMAS, IAPSO, and IACS, Paper 23316.

Gregg, M. C., and L. J. Pratt, 2010: Flow and hydraulics near the sill of Hood Canal, a strongly sheared, continuously stratified fjord. J. Phys. Oceanogr., 40, 1087-1105.

Helfrich, K., and L. Pratt, 2003: Rotating hydraulics and upstream basin circulation. J. Phys. Oceanogr., 33, 1651-1663.

Moum, J., 1996: Energy-containing scales of turbulence in the ocean thermocline. J. Geophys. Res., 101 (C6), 14 095-14 109.

Munk, W., 1966: Abyssal recipes. Deep-Sea Res., 13, 707-730.

Oppo, D. W., B. K. Linsley, Y. Rosenthal, S. Dannenmann, and L. Beaufort, 2003: Orbital and suborbital climate variability in the Sulu Sea, western tropical Pacific. Geochem. Geophys. Geosyst., 4, 1003, doi:10.1029/2001GC000260.

Polzin, K., K. Speer, J. Toole, and R. Schmitt, 1996: Intense mixing of Antarctic Bottom Water in the equatorial Atlantic Ocean. Nature, 380, 54-57.

Pratt, L. J., 1983: On inertial flow over topography. Part 1. Semigeostrophic adjustment to an obstacle. J. Fluid Mech., 131, 195-218.

— uniform potential vorticity. J. Phys. Oceanogr., 17, 2016-2029.

— Topographic Effects in the Ocean and Atmosphere. Springer, $589 \mathrm{pp}$.

— H. H. Deese, S. P. Murray, and W. Johns, 2000: Continuous dynamical modes in straits having arbitrary cross sections, with applications to the Bab al Mandab. J. Phys. Oceanogr., 30, 2515-2534.

- K. R. Helfrich, and D. Leen, 2008: On the stability of ocean overflows. J. Fluid Mech., 602, 241-266, doi:10.1017/ S0022112008000827.

Qu, T., and Y. T. Song, 2009: Mindoro Strait and Sibutu Passage transports estimated from satellite data. Geophys. Res. Lett., 36, L09601, doi:10.1029/2009GL037314.

_, Y. Du, and H. Sasaki, 2006a: South China Sea throughflow: A heat and freshwater conveyor. Geophys. Res. Lett., 33, L23617, doi:10.1029/2006GL028350.

_ J. B. Girton, and J. A. Whitehead, 2006b: Deepwater overflow through Luzon Strait. J. Geophys. Res., 111, C01002, doi:10.1029/2005JC003139.

Quadfasel, D., H. Kudrass, and A. Frische, 1990: Deep-water renewal by turbidity currents in the Sulu Sea. Nature, 348, 320-322. 
Ramp, S. R., and Coauthors, 2004: Internal solitons in the northeastern South China Sea. Part I: Sources and deep water propagation. IEEE J. Oceanic Eng., 29, 1157-1181, doi:10.1109/ JOE.2004.840839.

Ruddick, B., and D. Walsh, 1997: Variations in apparent mixing efficiency in the North Atlantic Central Water. J. Phys. Oceanogr., 27, 2589-2605.

Smith, W., and D. Sandwell, 1997: Global seafloor topography from satellite altimetry and ship depth soundings. Science, 277, 1957-1962.

Smyth, W., J. Moum, and D. Caldwell, 2001: The efficiency of mixing in turbulent patches: Inferences from direct simulations and microstructure observations. J. Phys. Oceanogr., 31 1969-1992.

Song, Y. T., 2006: Estimation of interbasin transport using ocean bottom pressure: Theory and model for Asian marginal seas. J. Geophys. Res., 111, C11S19, doi:10.1029/2005JC003189.

Thorpe, S., 1977: Turbulence and mixing in a Scottish loch. Philos. Trans. Roy. Soc. London, 286, 125-181.

—, 2005: The Turbulent Ocean. Cambridge University Press, $458 \mathrm{pp}$.
Thurnherr, A. M., 2006: Diapycnal mixing associated with an overflow in a deep submarine canyon. Deep-Sea Res., 53 (1-2), 194-206, doi:10.1016/j.dsr2.2005.10.020.

— , K. J. Richards, C. R. German, G. F. Lane-Serff, and K. G. Speer, 2002: Flow and mixing in the rift valley of the MidAtlantic Ridge. J. Phys. Oceanogr., 32, 1763-1778.

van Aken, H. M., I. S. Brodjonegoro, and I. Jaya, 2009: The deepwater motion through the Lifamatola Passage and its contribution to the Indonesian throughflow. Deep-Sea Res., 56, 1203-1216, doi:10.1016/j.dsr.2009.02.001.

Visbeck, M., 2002: Deep velocity profiling using lowered acoustic Doppler current profilers: Bottom track and inverse solutions. J. Atmos. Oceanic Technol., 19, 794-807.

Wesson, J., and M. Gregg, 1994: Mixing at Camarinal Sill in the Strait of Gibraltar. J. Geophys. Res., 99 (C5), 9847-9878.

Whitehead, J., 1989: Internal hydraulic control in rotating fluidsApplications to oceans. Geophys. Astrophys. Fluid Dyn., 48, 169-192.

Wyrtki, K., 1961: Physical oceanography of the Southeast Asian waters. Scripps Institution of Oceanography NAGA Rep. 2, 225 pp. 